\title{
Association of the presence of residual anti-Toxoplasma gondii IgM in pregnant women and their respective family groups in Miracema, Northwest Rio de Janeiro, Brazil
}

\author{
Ana Claudia Ribeiro/ ${ }^{+}$, Martha Suarez Mutis ${ }^{1}$, Octavio Fernandes $^{2}$ \\ Laboratório de Parasitologia, Instituto de Pesquisa Clínica Evandro Chagas-Fiocruz, Av. Brasil 4365, 21045-900 Rio de Janeiro, RJ, Brasil \\ 'Laboratório de Doenças Parasitárias ²Laboratório de Epidemiologia Molecular de Doenças Infecciosas, Instituto Oswaldo Cruz-Fiocruz, \\ Rio de Janeiro, RJ, Brasil
}

The seroprevalence of toxoplasmosis in 832 pregnant women in Miracema, Rio de Janeiro, was determined and $75.1 \%$ (625) and $2.0 \%$ (17) were anti-Toxoplasma gondii $\operatorname{IgG}$ and $\operatorname{IgM}$ positive, respectively. Out of the $17 \mathrm{IgM}$ positive pregnant women, only one had low avidity IgG corresponding to the acute phase of the infection. All the other women presented with high avidity IgG and also presented with residual IgM anti-T. gondii. Of this sample, 106 received home visits (this includes 11 family nuclei of pregnant women with residual IgM anti-T. gondii, 68 nuclei of only IgG positive pregnant women and 27 nuclei of pregnant women with no antibodies to anti-T. gondii), resulting in 267 individuals visited. Out of these 267 individuals, 21 were positive for $\operatorname{Ig} G$ and $\operatorname{IgM}$ anti-T. gondii and were candidates for the IgG avidity test. All of them presented with high avidity $\operatorname{Ig} G$ and residual IgM. Five of these IgM+ individuals were (5/238; $2.1 \%)$ relatives of IgM negative pregnant women. The other 16 (16/29; 55.2\%) were relatives of IgM+ pregnant women who were positive for residual IgM anti-T. gondii. This association was statistically significant $(p=0.0000)$. The analysis presented herein raises questions regarding the presence of residual IgM anti-T. gondii such as genetic determinants or even constant antigenic stimuli for the same family cluster.

Key words: toxoplasmosis - avidity antibody - pregnant women

The parasite Toxoplasma gondii is one of the most frequent to infect human beings and is found in almost one-third of the world population (Dubey 2004). Patients are frequently asymptomatic and toxoplasmosis has no relevant repercussions on the patient. However, infected fetuses and immunodeficient individuals may present with serious or even fatal clinical outcomes (Gross 1996, Vidigal et al. 2002). Toxoplasmosis infection is transmitted (1) by the ingestion of raw or undercooked meat, which contains tissue cysts of the parasite; (2) through the accidental ingestion of oocysts eliminated in the feces of infected cats; and (3) transplacentary due to the primary gestational infection (Frenkel et al. 1970, Hutchinson et al. 1971, Aspinall et al. 2003, Bahia-Oliveira et al. 2003).

The diagnosis of toxoplasmosis is based mainly on serological tests that detect anti-T.gondii $\operatorname{IgM}$ and $\mathrm{IgG}$ antibodies (Camargo 1995, Pinard et al. 2003), that correspond to acute and chronic infections, respectively. Although IgM anti-T. gondii (IgMTg) tend to disappear, it can remain at low titers for a long period of time complicating the interpretation of the serological diagnosis of the acute phase in that case they are named residual IgM and correspond to the chronic phase of the disease (Bastien 2002, Remington et al. 2004). In order to differentiate the two phases, an important step in defining

Financial Support: PPSUS-MS/CNPq/Faperj, CAPES

+ Corresponding author: ana.claudia@ipec.fiocruz.br

Received 2 January 2008

Accepted 8 September 2008 the implementation of specific therapy - the avidity test of IgG anti-T. gondii (AIgGTg) (Camargo 1995, Lappalainen \& Hedman 2004) can be used. High avidity antibodies (higher than $35 \%$ avidity) are indicative of the chronic phase and low avidity antibodies (lower than $30 \%$ avidity) are indicative of the acute phase.

In the present report, the prevalence of residual $\operatorname{IgM}$ in pregnant women from Miracema, Northwest of the state of Rio de Janeiro, Brazil (Table I) was investigated, as well as the correlation of these antibodies with $\mathrm{IgG}$ avidity, in the patients and in their family groups, in order to effectively establish the diagnosis of acute or chronic toxoplasmosis. The studied sample was chosen considering an estimated prevalence (IgGTg) of toxoplasmosis of $75 \%$ in order to identify the " $n$ " value necessary to obtain enough seronegative individuals to ensure that $25 \%$ of the sample would be candidates for being IgMTg positive during pregnancy. Consequently, in order to determine the sample size, the population of women in the municipally $(\mathrm{n}=13521)$, a prevalence of $25 \%$, an estimated error of $3 \%$, and a significance level of $5 \%$ were considered as parameters leading to a minimum sample of 756 pregnant women. Thus, from May 2003-December 2006, 832 pregnant women that visited the municipal public health system were selected and evaluated.

Serological tests were performed in order to detect IgMTg and IgGTg antibodies using a commercial enzyme linked immunosorbent assay Diesse $\AA$ (ELISA) kit in all pregnant women. This technique has $100 \%$ and $99.6 \%$ specificity and sensitivity, respectively, for detecting IgMTg and has $100 \%$ for both analytical parameters for IgGTg. The patients that were IgMTg and IgGTg posi- 
tive, regardless of the titers, were selected for the avidity test (AIgGTg, ELISA WAMA Diagnóstica ${ }^{\circledR}$ ) in order to determine whether the existing IgM really corresponded to the acute phase or whether it was indicative of residual $\operatorname{IgM}$. Moreover, not only were they tested for IgMTg and $\operatorname{IgGTg}$, but the relatives of the pregnant women were also tested. High avidity $\operatorname{IgG}$ was defined as presenting with avidity of $35 \%$ or more and low avidity IgG was characterized as presenting with avidity of $30 \%$ or less.

Frequency analyses, standard deviation, central trend measure and univariate and bivariate analyses were carried out. For categorical variables, the chi-square tests with Mantel-Haenszel corrections for proportions were performed and odds ratios were calculated to measure the significance of the statistical association between two categorical variables. All the statistical analyses were performed using the EPI INFO 2000 (CDC, Atlanta). In all cases, statistical significance was defined as $5 \%$.

Out of the 832 pregnant women, 625 (75.1\%) were IgGTg positive, with $608(73.1 \%)$ being IgMTg negative, and 17 (2.0\%) being IgMTg positive. Two hundred and seven $(207 / 832 ; 24.9 \%)$ were non-reactive for $\mathrm{IgGTg}$ and IgMTg. The 17 IgMTg and IgGTg positive pregnant women were subjected to the AIgGTg test. Only one

TABLE I

Serological Toxoplasma profile in 832 pregnant women of Miracema municipality

\begin{tabular}{|c|c|c|c|c|c|c|c|c|c|c|}
\hline & \multicolumn{6}{|c|}{ IgM serological tests } & \multicolumn{4}{|c|}{ Avidity tests $^{a}$} \\
\hline & \multicolumn{2}{|c|}{ Positive } & \multicolumn{2}{|c|}{ Negative } & \multicolumn{2}{|c|}{ Total } & \multicolumn{2}{|c|}{ Low } & \multicolumn{2}{|c|}{ High } \\
\hline & $\mathrm{N}^{\mathrm{o}}$ & $\%$ & $\mathrm{~N}^{\mathrm{o}}$ & $\%$ & $\mathrm{~N}^{\mathrm{o}}$ & $\%$ & $\mathrm{~N}^{\mathrm{o}}$ & $\%$ & $\mathrm{~N}^{\mathrm{o}}$ & $\%$ \\
\hline IgG positives & 17 & 2.7 & 608 & 97.3 & 625 & 75.1 & 1 & 5.9 & 16 & 94.1 \\
\hline IgG negatives & 0 & 0.0 & 207 & 100.0 & 207 & 24.9 & & & & \\
\hline Total & 17 & 2.0 & 815 & 98.0 & 832 & 100.0 & 1 & 5.9 & 16 & 94.1 \\
\hline
\end{tabular}

a: done only in pregnant women with $\operatorname{IgM}$ positive test.

TABLE II

Comparison of serological status by age groups and number of inhabitants for house the group of pregnant women $(n=106)$ and its relatives $(n=267)$

\begin{tabular}{|c|c|c|c|c|c|c|c|c|}
\hline \multirow{4}{*}{$\begin{array}{l}\text { Familiar Nuclei } \\
\text { pregnant women } \\
\text { Relatives }\end{array}$} & \multicolumn{2}{|c|}{$\operatorname{IgG}+$ and $\operatorname{IgM}+$} & \multicolumn{2}{|c|}{ IgG+ and IgM- } & \multicolumn{2}{|c|}{ IgG- and IgM- } & \multicolumn{2}{|c|}{ Total } \\
\hline & $\mathrm{N}^{\mathrm{o}}$ & $\%$ & $\mathrm{~N}^{\mathrm{o}}$ & $\%$ & $\mathrm{~N}^{\mathrm{o}}$ & $\%$ & $\mathrm{~N}^{\mathrm{o}}$ & $\%$ \\
\hline & 11 & 10.4 & 68 & 64.2 & 27 & 25.5 & 106 & 28.4 \\
\hline & 21 & 7.9 & 137 & 51.3 & 109 & 40.8 & 267 & 71.6 \\
\hline Total & 32 & 8.6 & 205 & 55.0 & 136 & 36.5 & 373 & 100.0 \\
\hline \multicolumn{9}{|c|}{ Age group of pregnant women } \\
\hline $13-19$ & 2 & 9.5 & 12 & 57.1 & 7 & 33.3 & 21 & 19.8 \\
\hline $20-29$ & 6 & 10.0 & 37 & 61.7 & 17 & 28.3 & 60 & 56.6 \\
\hline $30-39$ & 3 & 13.6 & 17 & 77.3 & 2 & 9.1 & 22 & 20.8 \\
\hline$>=40$ & 0 & 0.0 & 2 & 66.7 & 1 & 33.3 & 3 & 2.8 \\
\hline Total & 11 & 10.4 & 68 & 64.2 & 27 & 25.5 & 106 & 100.0 \\
\hline \multicolumn{9}{|c|}{ Age group of relatives } \\
\hline$<10$ & 2 & 2.0 & 15 & 15.3 & 81 & 82.7 & 98 & 36.7 \\
\hline '10-19 & 5 & 11.4 & 27 & 61.4 & 12 & 27.3 & 44 & 16.5 \\
\hline $20-29$ & 7 & 13.2 & 37 & 69.8 & 9 & 17.0 & 53 & 19.9 \\
\hline $30-39$ & 2 & 5.9 & 29 & 85.3 & 3 & 8.8 & 34 & 12.7 \\
\hline$>=40$ & 5 & 13.2 & 29 & 76.3 & 4 & 10.5 & 38 & 14.2 \\
\hline Total & 21 & 7.9 & 137 & 51.3 & 109 & 40.8 & 267 & 100.0 \\
\hline \multicolumn{9}{|c|}{ Number of dwellers/house ${ }^{a}$} \\
\hline 2 & 9 & 11.4 & 45 & 57.0 & 25 & 31.6 & 79 & 21.2 \\
\hline $2-4$ & 15 & 9.8 & 81 & 52.9 & 57 & 37.3 & 153 & 41.0 \\
\hline $5-9$ & 1 & 0.8 & 70 & 59.3 & 47 & 39.8 & 118 & 31.6 \\
\hline$>=10$ & 7 & 30.4 & 9 & 39.1 & 7 & 30.4 & 23 & 6.2 \\
\hline Total & 32 & 8.6 & 205 & 55.0 & 136 & 36.5 & 373 & 100.0 \\
\hline
\end{tabular}

$a$ : pregnant women and relatives. 
pregnant women $(1 / 17 ; 5.9 \%)$ presented with low avidity IgGTg. Therefore, this patient was characterized as being in the acute phase of the infection $(1 / 832 ; 0.12 \%)$. The other 16 (16/17; 94.1\%) presented with high avidity IgG and consequently the IgMTg was characterized as being residual IgM (Table I).

Of the 832 pregnant women evaluated in this study, $106(12.7 \%)$ received a home visit for serology tests of relatives residing in the same house. Two hundred and sixty-seven relatives participated in the study, totaling 373 individuals studied in 106 dwellings. Of the 106 $(106 / 832 ; 12.7 \%)$ family nuclei analyzed, 11 nuclei were of residual IgMTg pregnant women; 68 nuclei of pregnant women who were only IgGTg positive; and $27 \mathrm{nu}-$ clei of non-reactive pregnant women (Table II).

Considering the relatives of pregnant women, out of the 267 dwellers of the visited houses (of 106 pregnant women), $158(59.2 \%)$ tested positive for IgGTg, $137(137 / 267 ; 51.3 \%)$ tested positive for IgGTg and IgMTg negative and 21 (21/267; 7.9\%) were both IgGTg and IgMTg positive. The remaining dwellers (109/267; $40.8 \%$ ) were not reactive for IgGTg or IgMTg (Table II). Correlations with age groups revealed that $11.2 \%$ $(19 / 169)$ of the inhabitants 10 -years-old or older were IgM positive, while in children that were less than 10 -years-old, the prevalence was $2.0 \%(2 / 98)$ and that the difference was statistically significant $(\mathrm{p}=0.007)$. In addition, when the results of the avidity tests were compared between the two age groups (10-years-old or more and children that were less than 10-yearsold), a statistically significant difference was found $(p=0.000815)$, with higher avidity in the older group.

Interestingly, the number of individuals in the family cluster (pregnant women and their relatives, $\mathrm{n}=373$ ) also affected the result. IgMTg positivity was found in 30.4\% (7/23) of dwellers living with 10 or more individuals in the same house. In contrast, only $7.1 \%(25 / 350)$ of the individuals that were living with less than 10 individuals were IgMTg positive $(\mathrm{p}=0$ 00005) (Table II).

Twenty-one IgMTg and IgGTg positive relatives were subjected to the AlgGTg test and all presented with high avidity IgGTg. gondii and, therefore, were classified as having residual IgMTg. Five of these relatives $(5 / 21 ; 23.8 \%)$ belonged to 95 residences where the pregnant women were IgMTg negative and $16(16 / 21 ; 76.2 \%)$ were relatives of the 11 residual IgMTg positive pregnant women.

The 11 residual IgMTg positive pregnant women had 29 relatives. As previously mentioned, 16 of them (16/29; $55.2 \%)$ proved to be residual IgMTg positive. The family nuclei $(n=95 ; 95 / 106)$ in which the pregnant women were IgMTg negative included 238 individuals. Out of these, $233(233 / 238 ; 97.9 \%)$ were IgMTg negative as well. Only five $(5 / 238 ; 2.1 \%)$ of relatives of the IgMTg negative women were reactive for residual IgMTg.

Considering all the relatives that were positive for residual IgMTg, the difference between those that were relatives of residual IgMTg positive pregnant women $(16 / 29 ; 55.2 \%)$ and those that were relatives of IgMTg negative pregnant women $(5 / 238 ; 2.1 \%)$ was statistically significant $(\mathrm{p}=0.0000001)$ (Table III).

\section{TABLE III}

Association between serum prevalence (IgM) for toxoplasmosis of pregnant women (fixed) and IgM of the relatives and between serum prevalence of IgM for toxoplasmosis of relatives (fixed) and pregnant women

\begin{tabular}{lrrrrrr}
\hline & \multicolumn{3}{c}{ IgM+ } & \multicolumn{2}{c}{ IgM- } & \multicolumn{2}{c}{ Total } \\
\cline { 2 - 7 } & \multicolumn{9}{c}{ Relatives } \\
\cline { 2 - 7 } pregnant women & $\mathrm{N}^{\text {o }}$ & \multicolumn{1}{c}{$\%$} & \multicolumn{1}{c}{$\mathrm{N}^{\text {o }}$} & $\%$ & $\mathrm{~N}^{\text {o }}$ & $\%$ \\
\hline IgM+ (11/106) & 16 & 55.2 & 13 & 44.8 & 29 & 10.9 \\
IgM- (95/106) & 5 & 2.1 & 233 & 97.9 & 238 & 89.1 \\
\hline Total & 21 & 7.8 & 246 & 92.2 & 267 & 100.0
\end{tabular}

OR: 57.35 (IC 95\%: 16.28 - 216.19); $\mathrm{p}=0000001$.

\begin{tabular}{lrrrrrr}
\hline & \multicolumn{7}{c}{ pregnant women } \\
\cline { 2 - 7 } Relatives & $\mathrm{N}^{\text {o }}$ & $\%$ & \multicolumn{1}{c}{$\mathrm{N}^{\text {o }}$} & $\%$ & $\mathrm{~N}^{\text {o }}$ & $\%$ \\
\hline IgM+ $(21 / 267)$ & 9 & 60.0 & 6 & 40.0 & 15 & 14.2 \\
IgM- $(246 / 267)$ & 2 & 2.2 & 89 & 97.8 & 91 & 85.8 \\
\hline Total & 11 & 10.4 & 95 & 89.6 & 106 & 100.0
\end{tabular}

OR: 66.75 (IC 95\%: 9.82 - 591.65); $\mathrm{p}=00000000$.

In epidemiological surveys, the seroprevalence for toxoplasmosis has been reported to be above $50 \%$ in several regions in Brazil and the rest of the world, independently of the target population (Coutinho et al. 1981, Jeannel et al. 1988, Jenum et al. 1998, Tenter et al. 2000, Spalding et al. 2003, Heukelbach et al. 2007). The data presented here confirm the high prevalence of toxoplasmosis (75.1\%) in Miracema. Among all the studied pregnant women, only one was diagnosed with the acute phase of the disease. This pregnant women was followed-up with serological exams and remained IgMTg positive for a period of six months (data not shown). The low frequency of acute toxoplasmosis $(0.12 \%$ in the studied sample) is consistent with other studies that report an acute infection rate of $0.2-2.0 \%$, depending on the geographical region and dietary habits of the population such as ingestion of raw or undercooked meat (Wong \& Remington 1994, Silva et al. 2004, Singh \& Pandit 2004, De Paschale et al. 2008).

The application of IgMTg, IgGTg and AIgGTg was satisfactory in defining the diagnosis of toxoplasmosis in this study. The high seroprevalence was also found among the relatives of the pregnant women $(59.2 \%)$. This could be explained by (1) the exposure to the same risk factors; (2) the same hygiene conditions; and (3) the same food habits.

In the analysis of the results obtained from the family clusters, statistically significant positive relationships were found between pregnant women and relatives living in the same house for the presence of both residual IgGTg and residual IgMTg. These results can only be considered indicative of a positive relationship between positive pregnant women and relatives. This is because the generally high seroprevalence found in Miracema would be sufficient to explain positive serology of any individual, independent of being a relative of a pregnant women. 
The correlations found with age group revealed that children less than 10-years-old have more chance of being IgM negative. In addition, the correlation between the number of individuals in the same household and being IgMTg positive may be linked to poorer living conditions and poor hygiene in those dwellings. Both epidemiological features confirm that progressive exposure to risk factors for toxoplasmosis leads to higher seroprevalence for the disease.

Studies reporting residual IgM that hampered the serological diagnosis of toxoplasmosis do not justify its persistence. As a result of the analysis presented here, a few issues regarding residual IgM were raised, such as genetic determinants and whether constant antigenic stimuli for the same family cluster affected the results. In any case, more in-depth investigations are still required to shed more light on this intriguing finding.

\section{REFERENCES}

Aspinall TV, Guy EC, Roberts KE, Joynson DHM, Hyde JE, Sims PFG 2003. Molecular evidence for multiple Toxoplasma gondii infections in individual patients in England and wales: public health implications. Int J Parasitol 33: 97-103.

Bahia-Oliveira LM, Jones JL, Azevedo-Silva J, Alves CC, Orefice F, Addiss DG 2003. Highly endemic, waterborne toxoplasmosis in north Rio de Janeiro state, Brazil. Emerg Infect Dis 9: 55-62.

Bastien P 2002. Molecular diagnosis of toxoplasmosis. Trans $R$ Soc Trop Med Hyg 96 (Suppl.1): 205-215.

Camargo ME 1995. Alguns aspectos atuais do diagnóstico de laboratório da toxoplasmose. An Acad Nac Méd 155: 236-239.

Coutinho SG, Souza WJS, Camillo-Coura L, Marzochi MCA, Amendoeira MRR 1981. Levantamento dos resultados das reações de imunofluorescência indireta para toxoplasmose em 6.079 pacientes de ambulatório ou gestantes no Rio de Janeiro realizadas durante os anos de 1971 a 1977. Rev Inst Med Trop São Paulo 3: 48-56.

De Paschale M, Agrappi C, Clerici P, Mirri P, Manco MT, Cavallari S, Vigano EF 2008. Seroprevalence and incidence of Toxoplasma gondii infection in the Legnano area of Italy. Clin Microbiol Infec 14: 186-189.

Dubey JP 2004. Toxoplasmosis - a waterborne zoonosis. Vet Parasitol $126: 57-72$.

Frenkel JK, Dubey JK, Miller NL 1970. Toxoplasma gondii in cats: fecal stages identified as coccidian oocysts. Science167: 893-896.
Gross U 1996. Toxoplasma gondii research in Europe. Parasitol Today 12:1-4.

Heukelbach J, Meyer-Cirkel V, Moura RCS, Gomide M, Queiroz JAN, Saweljew P, Liesenfeld O 2007. Waterborne toxoplasmosis, Northeastern Brazil. Emerg Infect Dis. 13: 287-289, available at http://www.cdc.gov/eid/content/13/2/pdfs/287.pdf.

Hutchison WM, Dunachie JF, Work K, Siim JC 1971. The life cycle of the Coccidian parasite, Toxoplasma gondii, in the domestic cat. Trans R Soc Trop Med Hyg 65: 380-399.

Jeannel D, Niel G, Costagliola D, Danis M, Traore BM, Gentilini M 1988. Epidemiology of toxoplasmosis among pregnant women in the Paris area. Int J Epidemiol 17: 595-601.

Jenum PA, Stray-Pedersen B, Melby KK, Kapperud G, Whitelw A, Eskild A, Eng J 1998. Incidence of Toxoplasma gondii infection in 35,940 pregnant women I Norway and pregnancy outcome for infected women. J Clin Microbiol 36: 2900-2906.

Lappalainen M, Hedman K 2004. Serodiagnosis of toxoplasmosis. The impact of measurement of IgG avidity. Ann Ist Super Sanita 40: 81-88.

Pinard JA, Leslie NS, Irvine PJ 2003. Maternal serologic screening for Toxoplasmosis. J Midwifery Womens Health 48: 308-316.

Remington JS, Thulliez P, Montoya JG 2004. Recent developments for diagnosis of toxoplasmosis. J Clin Microbiol 42: 941-945.

Silva GRS, Silva DAO, Mineo JR, Ferreira MSA 2004. Comparative study of congenital toxoplasmosis between Public and Privete Hospitals from Uberlândia, MG, Brazil. Mem Inst Oswaldo Cruz 99: 13-17.

Singh S, Pandit AJ 2004. Indice and prevalence of toxoplasmosis in Indian pregnat women: a prospective study. Am J Rep Immunol 52: $276-283$.

Spalding SM, Amendoeira MRR, Ribeiro LC, Silveira C, Garcia AP, Camilo-Coura L. 2003. Estudo prospectivo de gestantes e seus bebês com risco de transmissão de toxoplasmose congênita em município do Rio Grande do Sul. Rev Soc Bras Med Trop 36: 483-491.

Tenter AM, Heckeroth AR, Weiss LM 2000. Toxoplasma gondii: from animals to humans. Int J Parasitol 30: 1217-1258.

Vidigal PVT, Santos DVT, Castro FC, Couto JCF, Vitor RWA, Brasileiro Filho G 2002. Prenatal toxoplasmosis diagnosis from amniotic fluid by PCR. Rev Soc Bras Med Trop 35: 1-6.

Wong SY, Remington JS 1994. Toxoplasmosis in pregnancy. Clin Infect Dis 18: 853-861. 